\title{
The new Gold Coast Chinatown: stakeholders' development preferences
}

\author{
Karine Dupre and Bixia Xu
}

Karine Dupre is Associate Professor and Bixia $\mathrm{Xu}$ is Endeavour Fellowship, both at the Urban Research Program, Griffith University, Gold Coast, Australia.
() International Tourism Studies Association

All figures and tables are produced by the authors of this paper.

\begin{abstract}
Purpose - The purpose of this paper is to study the relationship between culture-based tourism development and cultural sustainability in the established tourism destination of Gold Coast, Australia. It seeks to contribute to the debate on local development and tourism through evaluating the development of the newly-born Gold Coast Chinatown.

Design/methodology/approach - Two types of analysis were developed for this study. The first one aims at assessing the general features of the case study site. It was done by the urban analysis of the precinct, the count of the shops associated with the identification of their function (e.g. retail, services, etc.), street visual survey, and the assessment of ethnic expression/representations. The second analysis aims at assessing place-attachment, development impacts and cultural attitude. It was done by questionnaire surveys.

Findings - The analysis evidences mainly two findings. First, tradition, authenticity or ethnicity are not perceived as key drivers, and tangible pre-requisites do not appear as a priority for a culture-based tourism development. Second, correlation studies show the longer the length of residence the higher is the attitude towards positive perceived economic impacts and positive cultural attitudes. It is the opposite of what is usually found in literature review. As such, it challenges the concept of cultural sustainability, and helps us to reconsider the weight of the evaluative factors of community attachment, development impact and cultural attitude in tourism development.

Originality/value - The recent creation of the Gold Coast Chinatown not only raises the question of the rationale of what is usually recognised as a community-based settlement, hence its cultural foundation and the legitimacy of transfer of cultural models, but also the processes at stake between cultural sustainability and tourism development. To the knowledge, no publication exists on this case study.
\end{abstract}

Keywords Australia, Tourism development, Cultural sustainability, New Chinatown, Stakeholder development, Stakeholder preferences

Paper type Case study

\section{Introduction}

Australia is a competitive tourist destination which is proved by its 5.9 million international visitors in 2013 (TRA, 2014). This represents the equivalent of 25 per cent of the residential population of the country. Major shifts occurred in governmental directives after the year 2000 to accommodate changes at the local and global level. For example, after a period of continuous growth in the number of domestic visitors of the cultural and heritage tourism markets, it was decided that Australia's natural and cultural assets become major draw cards for international and domestic visitors (TRA, 2008). Authorities at the different levels of the tourism industry developed new scopes or improvements to more efficiently attract international cultural and heritage visitors. The latter comprised half of all the international visitors to Australia in 2009 (2.6 million) and the number remains relatively steady with an average annual growth of 2 per cent in this market since 2000 (TRA, 2014). On the other hand, other perspectives also opened with changes occurring in China since the 1980s and the rapid development of its tourism industry. Australia was one of the first western destinations to receive the Approved Destination Status 
(ADS) in 1999, allowing ADS group leisure travel to Australia from China (TRA, 2013). Since 2002, arrivals from China have achieved an annual compound growth rate of 13 per cent, placing Chinese tourists as Australia's second largest inbound market (TRA, 2013). This has consequences not only on how to develop the market, but also on how to culturally increase incentives to better understand these specific visitors. It also questions the impact it has on the local community, and how much it is yearning for such market development.

Tourism studies offer plenty of literature about the relationship between tourism and local development, with a strong emphasis on the issue of sustainability in relation to the impact of tourism since the 1990s. Critical scholars have questioned the framework, the meaning and usability, with which sustainability has become an important policy issue in tourism development (Saarinen, 2006; Liu, 2003; Sharpley, 2000). The idea here is not to produce a discursive essay, but rather an empirically based article with a case study that relies on culture as the main incentive for local and tourism development. Indeed, the recent creation of the Gold Coast Chinatown not only raises the question of the rationale of what is usually recognized as a community-based settlement, hence its cultural foundation and the legitimacy of transfer of cultural models, but also the processes at stake between cultural sustainability and tourism development. After a contextual presentation of the Gold Coast Chinatown, this paper presents the method developed for the project, along with its first results, followed by a discussion and conclusion.

\section{A new Chinatown: the Gold Coast context and development preferences}

Numerous scholars have contributed to the research body on Chinatowns (Anderson, 1991; Wong, 2004; Christiansen, 2003) and, if disciplinary approaches vary, there is a consensus about the purpose of Chinatowns outside China: "a world of their own for Chinese migrants where they could speak their own language and felt secure" (Wu, 1928/1991). Yet, society changes and new theoretical perspectives have contributed to identify that Chinatowns today are not just sites where Chinese emigrants adapt to living in a non-Chinese society, they are also sites for tourism and local development (Tan, 2013). Some have described how powerful the tourism lever is through the growth of some Chinatowns, such as in Singapore (Woon, 2000) or Lisbon (Mota Santos, 2013), while others have given evidence that a Chinatown contributed to a city's redevelopment such as with Paris (Chuang and Trémon, 2013) or La Havana (Hearn, 2013). However, these types of contributions underline that one contemporary major shift concerns the actual residences of the Chinese locals. They might not live in Chinatowns anymore (to see an extensive analysis of that phenomenon, see e.g. Christiansen, 2003). In the same way as Chinese settlements were not necessary needed to create Chinatowns, there are other factors, such as "activities" or "symbolic of place" that play a significant role today in identifying Chinatowns. In this context, the concept of authenticity not only triggers questions on identity, representations, and perceptions, but also relates to the construction of the place (from its social historicity to its physical features) in a more global approach, as suggested by Taylor (1991). For the latter, "authenticity is not the enemy of demands that emanate from beyond the self; it presupposes such demands". But as such, a gap might still exist between the persistence of cultural norms and perceptions of Chinatowns and their reality. The growing request of tourists towards authentic, "real" or "honest" places has increased attention on authenticity for tourism project developments, with more or less developed interest on the consequences of attitude, preference, and acceptance of the community.

\section{The Gold Coast context}

Like all cities in Australia, the city of Gold Coast was developed with the European colonisation of the country and the successive waves of migration. However, unlike other Australian cities, Gold Coast had a very early orientation towards tourism that reached a peak in the 1960s and has not decreased since with more than 12 million visitors annually according to the most recent census data from the Australian Bureau of Statistics (ABS, 2011). The Gold Coast is renowned for its natural environment (57 kilometres of coastal strip with beautiful beaches and unique hinterland featuring several national parks) and its leisure oriented facilities with a large number of theme parks, resorts, and shopping centres. However, with a population that can also triple in size over 
the holiday season in selected precincts, the city has historically been challenged by finding a balance between its financial interests, community cohesion, and identity. With the reputation of the city "as a symbol of excess, extravagance, tackiness, and placelessness" (Weaver and Lawton, 2004) along with the pro-development attitude of the state government and the abundance of entrepreneurial initiatives (Dedekorkut-Howes and Bosman, 2015), it raises many questions about the city governance, for instance, (Dredge and Bosman, 2011; Wise, 2006) or its planning schemes (Dredge and Jamal, 2013; Griffin, 2006).

In 2013, the city of Gold Coast announced its first plans for the creation of a Chinatown in Southport, which is one of the oldest precincts of the city. It is envisioned as the place that will "bring a sense of home and community to the thousands of permanent residents, and international students studying at Gold Coast universities, English language schools and colleges, and support Chinese and Asian visitors to our city. Gold Coast Chinatown will be true to the Gold Coast spirit and will represent our new world relationship with the Asia-Pacific region". Conceived and developed as a part of a broader plan to revitalise Southport as the central business district of the Gold Coast, one of the particularities of this new Chinatown is not to be frontally acknowledged as a tourism development but rather as "a place to do business, to be entertained, to live, and be educated" with an objective to "enhance the tourism product of the city and its cultural diversity". This is surprising since the tourism industry in Southport displays quite a good position and a continuous growth as a sector of employment: in 2011, it occupied 29.4 per cent of the employed population of Southport (accommodation and food service, retail trade, and art and recreation) instead of the 28.1 per cent in 2006 (ABS, 2006, 2011). Could it be that authorities feel that residents might negatively perceive the potential impacts of a growing tourism industry in this precinct?

Furthermore, immediate questions arise regarding the artificial creation of what is usually recognised as a community-based settlement, since the Gold Coast has had quite a recent development of Chinese migrants and uses this cultural norm regarding Chinatown as a foundation reason. Indeed, although Chinese migrants on the Gold Coast today represent an increase of 31 per cent over a sole decade (2001-2011), Chinese-born residents represented only 0.7 per cent of the population of the city in 2011. This compares with 6.5 per cent for Sydney and 3.1 per cent nationwide (ABS, 2014). There is quite a discrepancy with the statement of the official brochure of the Chinatown project development ("By the 1990s the Gold Coast had a large, strong Chinese community") thus maybe evidencing a discursive bias to confer authenticity to the project. Also, no ethnic territoriality or enclave sustains the choice of the location of the newly born Chinatown. The project consists of the rejuvenation of mainly two existing streets (Davenport and Young Streets) in one of the oldest urban fabrics of the city. Although Southport is a mixed precinct in terms of ethnicity and birthplace, it remains in majority an Australian-born precinct (55.2 per cent in 2011, ABS) despite the noticeable change over the last decade (63.7 per cent in 2001, ABS). The later can be explained by the increase of Asian-born residents over the same decade (multiplied by 2.5 between 2001 and 2011) but these residents still are a minority: Chinese-born residents represent only 2.7 per cent of the whole district population with no evident spatial concentration. Yet the combination of South-Korea, China, Japan, and Hong Kong born residents today amounts for 7.8 per cent, which is slightly over the number of the traditional first majority ethnic group that is New Zealand (7.2 per cent in 2011 and 2001, ABS). As such, the Chinatown development seems much more reliant on recent dynamic Asian immigration than on a historical and existing strong Chinese community.

Nevertheless, it does not mean that this community has achieved nothing. First discussions about developing a Chinatown can be traced back to the late 1990s, under its initiative early plans envisioned the suburb of Mermaid Beach or Surfers Paradise to host the Chinatown. Today the Gold Coast Chinatown Association is one of the main key stakeholders in the development project, which received approval and funding from the Queensland State (Minister for Tourism) and the city of Gold Coast (approximately four million dollars).

Knowing that most of the Chinatowns developed in Australia were a result of a large influx of Chinese migrants who were driven by a system of indentured labour and then the gold rushes in the 1850s, the Gold Coast Chinatown project addresses the relationships between tourism development and community, as well as the construction of traditions in a new context. Because 
there has been recent concern about Australian Chinese cultural heritage, some Chinatowns are heritage listed and others have been restored. Nonetheless the relations between cultural incentive and project development for newly developed Chinatowns have not attracted much research interest in Australia to date. This is exactly what this research seeks to survey, based on two types of analysis: the current site features of the Gold Coast Chinatown and the perceptions of visitors and local businesses. The final goal is to assess how the Gold Coast Chinatown stakeholders position the project against cultural sustainability.

\section{Method}

\subsection{Theoretical background}

Literature review shows evidence that cultural sustainability is still a difficult concept to define, although there is consensus regarding the components of sustainable development. Often understood as holistic (Spaling and Dekker, 1996), and inscribed in a timeline - "the continuity of cultural values linking all of the past, the present and the future" (Al Hagla, 2005), the concept also speaks of environment, society, and economy (e.g. Laroche, 2005; Birkeland, 2008; Throsby, 2008; Hawkes, 2001). Yet in this project, the choice was deliberately to adopt a "grounded theory" approach, which seeks to let the data tell the story without any pre-conceived notions (McKercher et al., 2005; Knigge and Cope, 2006). As such, it was hoped that all the subjectivities expressed in the results might lead to new ways to draw conclusions, as well as drawing evidence from original discursive elements of cultural sustainability.

On the other hand, numerous scholars have discussed how to measure the impacts of the tourism industry and their outcomes. The Impact Assessment Theory has been considered due to its structuring and links with sustainability (Lawrence, 2000; Nooteboom, 2007; Thomas and Elliott, 2005; Wathern, 2004). A commonly used research method to test the Impact Assessment Theory is questionnaire surveying (Lawrence, 2000). Because of the cultural foundation of the project (relying on the overseas traditional expression of Chinese culture), cultural attitude is used as one of the key elements to explore how stakeholders perceive development impacts, and place attachment and awareness on the project. This research also seeks to examine whether stakeholder perceptions are different according to age, income, nationality, and/or length of residence, as inspired by some studies that have explored this path (Williams et al., 1995; Sheldon and Var, 1984; Um and Crompton, 1987).

Yet, research has shown that stakeholders (not only tourists but also residents of local communities that attract tourists) hold diverse opinions about tourism's impacts and tourism development (Mason and Cheyne, 2000). For instance, Murphy (1988), Prentice (1993), and Hearne and Salinas (2002) argued that local communities will place a high preference on environmental quality when decisions on economic development are to be made. Prentice's (1993) research reported general support on the part of residents for policies of job creation through tourism development, but this support did not generally extend to the conspicuous expenditure of locally generated public resources on tourism development. Additionally, some previous tourism studies found that the tourists' and residents' attitude in terms of environmental, socio-cultural, and economic impacts have affected their acceptance to local tourism development (Murphy, 1988; Perdue et al., 1987). Local communities are greatly influenced by their economies. Job creation or reduced unemployment has been discussed as the most prominent benefit of tourism development. Based on a systematic tourism literature review (Akis et al., 1996; Harrill, 2004; Jurowski et al., 1997; Lindberg and Johnson, 1997; Lu and Var, 1986; McCool and Martin, 1994; Perdue et al., 1987; Sheldon and Var, 1984), understanding tourists' and residents' attitude and development preference is essential in achieving the goal of favourable community acceptance to local tourism development. Support and acceptance to tourism development from the community is essential for the successful operation and sustainability of tourism.

In fact, tourists' and residents' attitude towards tourism and its impacts have changed. Lankford and Howard (1994) observed that tourism research of the 1960s focused on the positive aspects of tourism, the 1970s emphasised the negative, while since 1980 onwards there has been a balanced level and systematic approach. The changing attitude and perceptions on tourism 
development and the growing understanding of the impacts of tourism have influenced approaches to tourism planning. Particularly, tourism stakeholders as key players in local communities, as their perceptions are critical when implementing further tourism planning and development (Brown, 2006). Consequently, as the success and sustainability of tourism development relies on the extent to which the development is planned and constructed with the knowledge and support of the tourism stakeholders. Although the impacts of tourism development are clear, there is a negligence of research toward the attitude, preference, and acceptance of stakeholders (tourists and residents in this research) to new cultural tourism attraction (such as Chinatowns) development. Therefore, to help redress the dearth of knowledge of stakeholder perceptions regarding cultural tourism attraction development, the purpose of this study was to extend past research by investigating the newly established Chinatown on the Gold Coast in Australia.

Based on the research questions proposed above (see Figure 1 for the flow of research design), the following seven hypotheses have been developed to be tested in this study:

H1. The perceived economic impacts of stakeholders affect their development preferences regarding Gold Coast Chinatown.

H2. The cultural attitudes of stakeholders affect their development preferences regarding Gold Coast Chinatown.

H3. The perceived place attachment of stakeholders affects their development preferences regarding Gold Coast Chinatown.

H4. There is a difference in development preferences regarding Gold Coast Chinatown for young, middle-aged, and old participants.

H5. There is a difference in development preferences regarding Gold Coast Chinatown for low, middle, and high-income participants.

H6. There is a difference in development preferences regarding Gold Coast Chinatown for Australian, Asian, and other nationality participants.

H7. There is a difference in development preferences regarding Gold Coast Chinatown for short, medium, and long-term residence participants.

\subsection{Survey instruments}

Two types of analysis were developed for this study. The first aims to assess the general features of the case study site. This was performed through the urban analysis of the precinct, the count of the shops associated with the identification of their function (e.g. retail, services, and others), a street visual survey, and the assessment of ethnic expression/representations. As such it evaluates the discursive representation of Chinese-ness by local authorities, as well as the potential mechanisms of spatial and symbolic appropriation by Chinatown businesses.

The second analysis aims at assessing place-attachment, development impacts and cultural attitude. This was performed by survey. There is no existing stakeholder questionnaire that could have been adopted for this study. Consequently, two new Chinatown survey instruments were developed: one for the Chinatown visitors and the other one for the businesses present in the Chinatown perimeter, indifferently addressed to owners and renters. These surveys were designed according to Fink's (2006) guidelines for effective survey research.

Each survey comprises 30 questions, includes single choice questions and Likert-scale measures, and is almost identical. For both visitors and businesses, identical questions were proposed to measure perceived development impacts, cultural attitudes, and socio-demographic information (age, occupation, education level, income, nationality, gender, and length of residence). Information was also gathered on how to make the local Chinatown a memorable experience to tourists and local residents and, for both surveys, one open-ended question was included asking for any comments. Distinction is introduced in the visitor's survey with questions about awareness of the proposed Chinatown, whereas in the business survey only, some questions focused on place-attachment. 


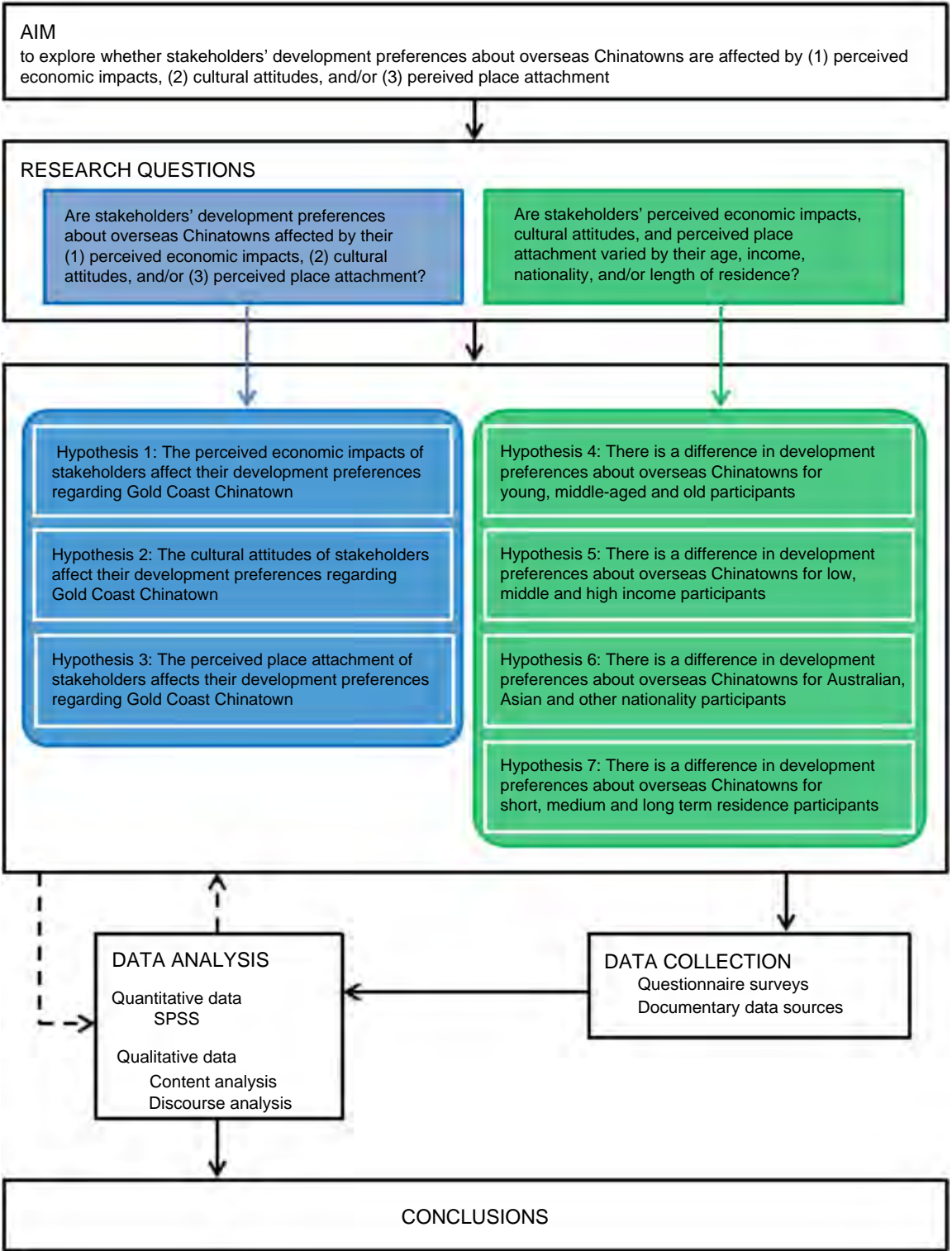

\subsection{Data collection and entry}

Questionnaires for both business and visitor surveys used self-report instruments. For the business survey, the entire population of businesses in the Gold Coast Chinatown precinct was 77 according to the tenancy survey conducted by the research team. Therefore, all 77 businesses were recruited as participants of the business survey. A drop-off recruitment method was adopted and each nominated business received a survey package, which included a cover letter/information sheet and a copy of the Chinatown business questionnaire to be collected by the researchers upon completion. Business survey questionnaires were dropped at each nominated business/shop on the 5 September, 2014. For those who did not reply to the drop-off business survey in the first round, a follow-up procedure was used to reduce the coverage bias. From the 5 to the 13 September 2014, 47 questionnaires were returned, yielding an overall response rate of 61 per cent. 
For the visitor survey, the entire population of visitors to the Chinatown (or Southport CBD) was unavailable and no visitor records were found. Generally, for a given confidence level (normally 95 per cent), the larger the sample size, the more reliable the answers are as a reflection of the population. Due to the lack of visitor population data, the sample size of the research could not be defined using the Confidence Level and Confidence Interval systems (Creative Research Systems, 2014). Taking consideration of generalisability, the researchers adopted recommendations from Stevens (1996) and Tabachnick and Fidell (2007) with regards to defining a suitable sample size for the social science research. Stevens (1996) suggests that for social science research, about 15 subjects per predictor are needed. Tabachnick and Fidell (2007) recommend a formula for calculating sample size requirements, taking into account the number of independent variables that researchers want to test: $N>50+8 \mathrm{~m}$ ( $\mathrm{m}=$ number of independent variables). In this research, as shown in the hypothesis section, there are four independent variables, namely age, education level, income, and length of residence. Hence, according to Stevens (1996), and Tabachnick and Fidell (2007), the minimum sample size would be 60 and 82, respectively. Therefore, in order to maximise the generalisability of the research within our research budget and time limitations, the research team decided to start with a sample of 100 visitor questionnaires for the Gold Coast Chinatown precinct. Convenience sampling was used to recruit participants for the visitor surveys. Participants were to be at least 15 years old. According to Patel et al. (2003), there is still potential bias in probability sampling: non-response bias, coverage bias, and selection bias. Non-response bias occurs when the observed value deviates from the population parameter due to differences between respondents and non-respondents. This type of bias is unavoidable. However, survey was undertaken until the number of 100 completed questionnaires (in full or at least more than half completed) was reached. To address the other two major types of bias, the following efforts were made in the sampling process to minimise bias. First, with regards to coverage bias, a survey perimeter of 150 meters around the Gold Coast Chinatown was established in which surveyors randomly travelled. Second, the surveys were conducted at different times of the day and the questionnaires were proposed in English or Chinese to minimise the selection bias.

In-person recruitment was chosen for the visitor survey. Survey conductors first explained the purpose and the nature of participation to the respondents. Every respondent was required to complete a questionnaire under the supervision of survey conductors. To ensure randomness, two strict rules were followed: if the potential survey respondents were in groups, the one who had the shortest physical distance to survey conductors was asked to complete the questionnaire survey, and when one questionnaire was completed, after checking through the questionnaire for completeness and legibility, survey conductors were to immediately stop the next eligible person passing by to conduct a new questionnaire. The 100 copies of visitor survey questionnaires were completed between the 5th and 9th of September, 2014, on-site.

After completion of data collection, the intercept survey questionnaires $(n=100)$ and returned businesses' questionnaires $(n=47)$ were entered into two Microsoft Excel databases. Unanswered questions were left blank in the databases; errors in responses were reported as errors. Information from both databases was exported to the IBM SPSS Statistics software for analysis. Data analysis began with frequency counts and percentages on all sociodemographic and visitation patterns in the survey data, followed by correlations to test $\mathrm{H1}$ $\mathrm{H} 3$ and analysis of variances (ANOVAs) to test $\mathrm{H} 4-\mathrm{H} 7$ (see Figure 2). The relationship between the hypotheses was investigated using the Pearson product-moment correlation coefficient. Preliminary analysis was performed to ensure there were no violation of the assumptions of normality, linearity, and homoscedasticity. The data analysis results are reported in next section.

\section{Results}

Findings from the two surveys are presented in the following sequence: site features; general characteristics from the stakeholder survey; and testing hypotheses using SPSS. Further discussion and analysis of these findings will be presented in the final section.

\begin{tabular}{l|l|l} 
VOL. 1 NO. 22015 & INTERNATIONAL TOURISM STUDIES ASSOCIATION & PAGE 7
\end{tabular} 


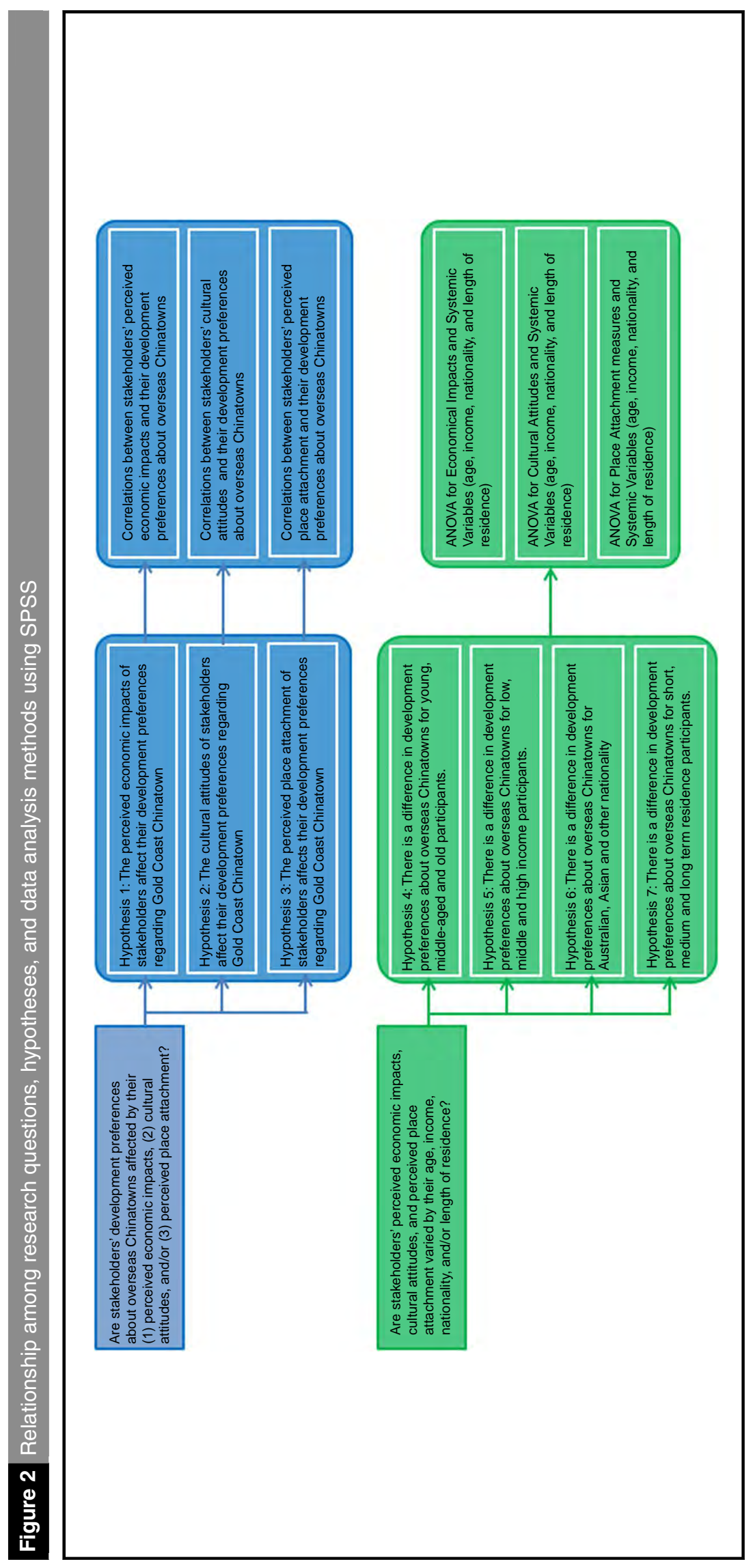

\begin{tabular}{l|l|l} 
PAGE 8 & INTERNATIONAL TOURISM STUDIES ASSOCIATION & VOL. 1 NO. 22015
\end{tabular} 


\subsection{Site features}

The Gold Coast Chinatown is located in a fairly busy precinct - Southport - that combines mixed activities (administrations, education activities, various businesses, and a major local shopping mall) and enjoys proximity with sufficient parking areas, bus services, and the new light rail. It is also close to a concentration of educational institutions that provide many services to a large number of the Asian population (e.g. TAFE, English language schools, and immigration services). The designed project incorporates three existing streets (Young Street, Davenport Street, and a part of Nerang Road) and their "Chinese-ation", but the work is mostly aimed towards streetscape - pavement, greenery, street lights - and external features since the urban fabric is already set, mostly that of typical Australian shops and warehouse typologies (see Figure 3). As such there is little impact of a discursive representation of what it may seem as Chinese-ness to local authorities. Twin cities have been called for some design features (mostly the gates), but emphasis to a "modern" representation was chosen. For example, the design of the gates reveals a strong contemporary interpretation or representation of gates (see Plate 1), yet at the moment none of them has been established.

Of the 74 land ownerships on the site, there are 77 businesses/shops and no residential function. The main represented activities are "services" (37 per cent) that includes massage services, restaurants, bars, hairdressers, and alteration and shoe repair stores. Next are "stores" and "offices" (around 20 per cent for both). But remarkably, at the date of the survey, almost 25 per cent of the businesses were "empty" (for lease or sale). With a majority of all these activities taking place at the ground floor (over 71 per cent), it influences the feeling of a site lacking in dynamism. The visual survey was conducted without any interview to verify ownership or nationalities of business/shop owners, but assessed what "appears" Asian and Chinese in terms of signage and decoration, as well as what was clearly identified as Asian or Chinese by the evident writing (see Figure 4). Visually, only 12 per cent of the shops appeared being from Asian origin; among them 2 per cent are Chinese.

\subsection{General characteristics from the stakeholder survey}

3.2.1 Socio-demography. The age of the surveyed visitors ranged from 16 to 94 years with a mean age of 32 , with a slight majority of male respondents at 59 per cent. Most visitor-survey respondents were middle-aged, very well-educated students, who earned below average incomes and had lived in the questionnaire city for more than one year at the time the surveys were conducted.

Similarly, the mean age of the people surveyed in the local businesses survey was 38 with a range from 15 to 74 years of age (see Table I), with a majority of female respondents at 62 per cent. According to the results of analysis of the survey participants' socio-demographic characteristics, most business survey respondents were middle-aged, well-educated, Gold Coast born, local business employees, who earned an average income and had lived in the city for more than one year at the time the surveys were conducted.

3.2.2 General attitudes. In both surveys, results show quite a positive attitude from the various respondents to development impacts and cultural attitudes for the Gold Coast Chinatown. The majority agreed that the Chinatown will create jobs for the local community (62 per cent for business respondents, 76 per cent for visitors; the same order is respected here after), attract investment (64/76 per cent) and give economic benefit to locals and businesses (64/78 per cent). Similarly the majority agrees or strongly agrees the new Chinatown will encourage a variety of cultural activities (66/82 per cent), result in more cultural exchanges (57/85 per cent) and give positive impacts on the cultural identity of the local community (63/71 per cent). However, there were less clear-cut answers for questions that challenged development impacts and cultural attitudes, with a higher respondent number who neither disagree nor agree (see sample Table II).

3.2.3 Visitation patterns (visitor survey only). Awareness and frequency of visits. In the visitor survey, only 26 survey respondents were tourists (26.26 per cent), whereas 73.74 per cent were local residents. However, all together 76 per cent had already visited the precinct before and 85 per cent planned to visit it again in the future. Among the residents, only 80.56 per cent of 


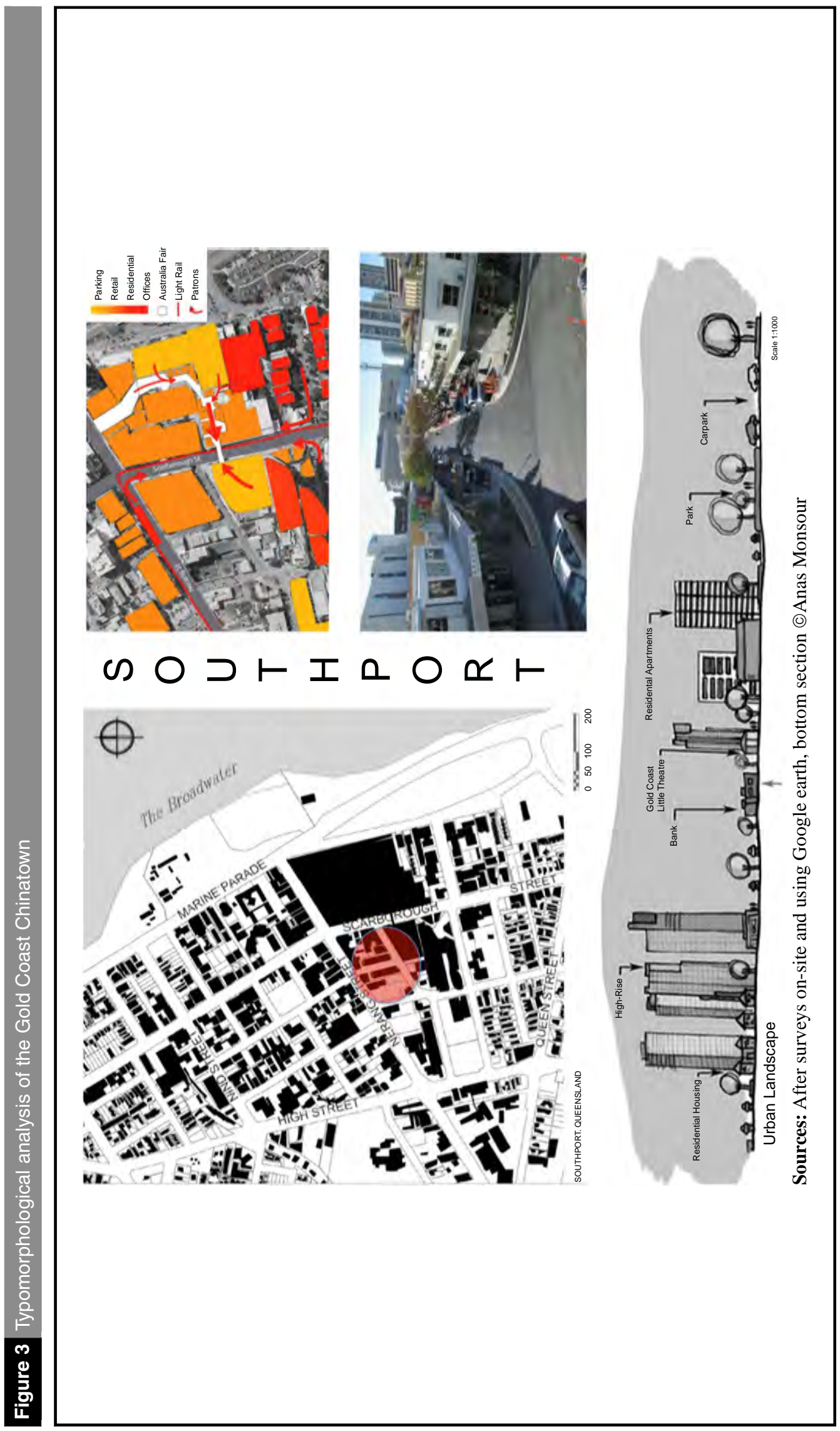

\begin{tabular}{l|l|l} 
PAGE 10 & INTERNATIONAL TOURISM STUDIES ASSOCIATION & VOL. 1 NO. 22015
\end{tabular} 


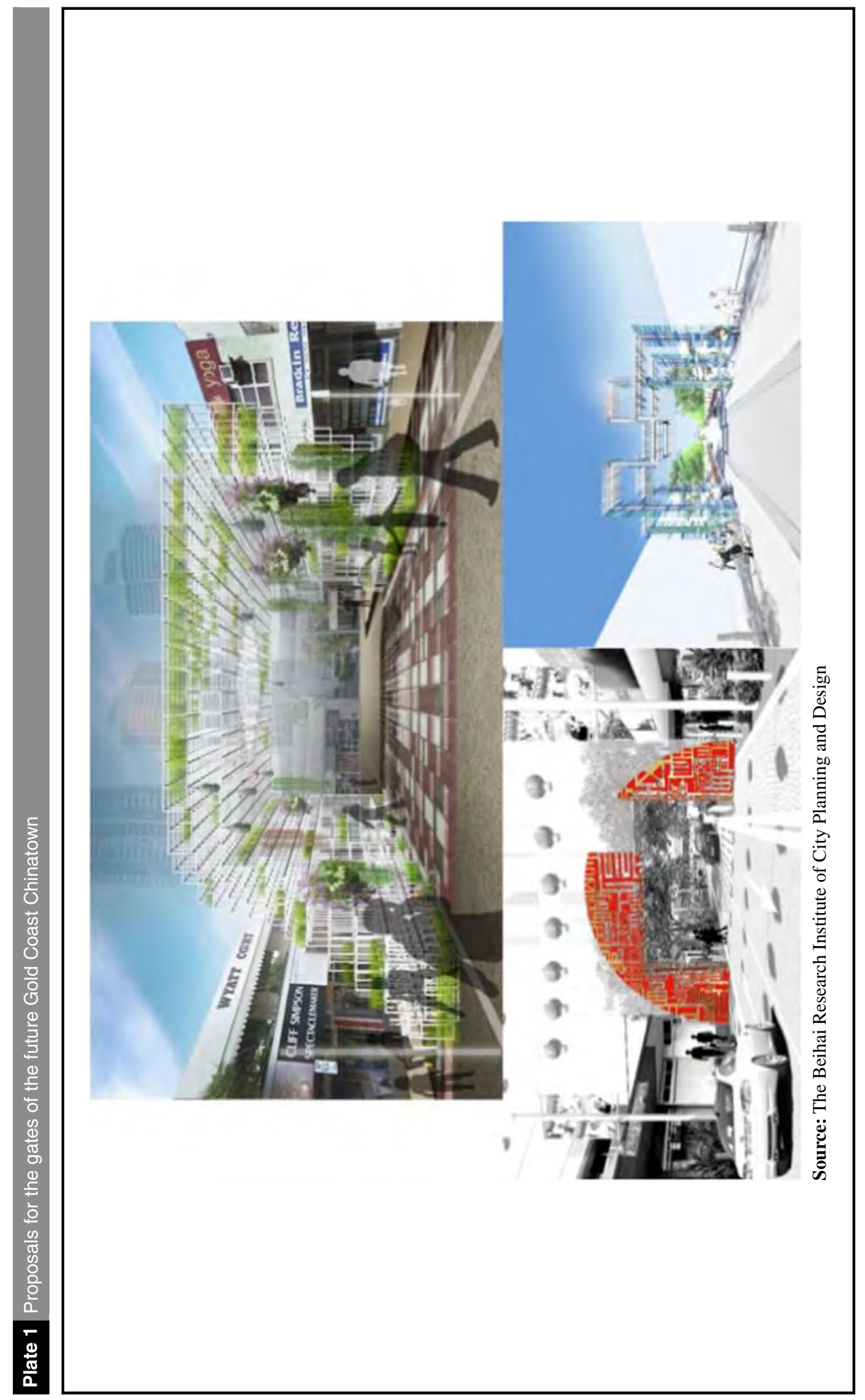

\begin{tabular}{l|l|l} 
VOL. 1 NO. 22015 & INTERNATIONAL TOURISM STUDIES ASSOCIATION & PAGE 11
\end{tabular} 


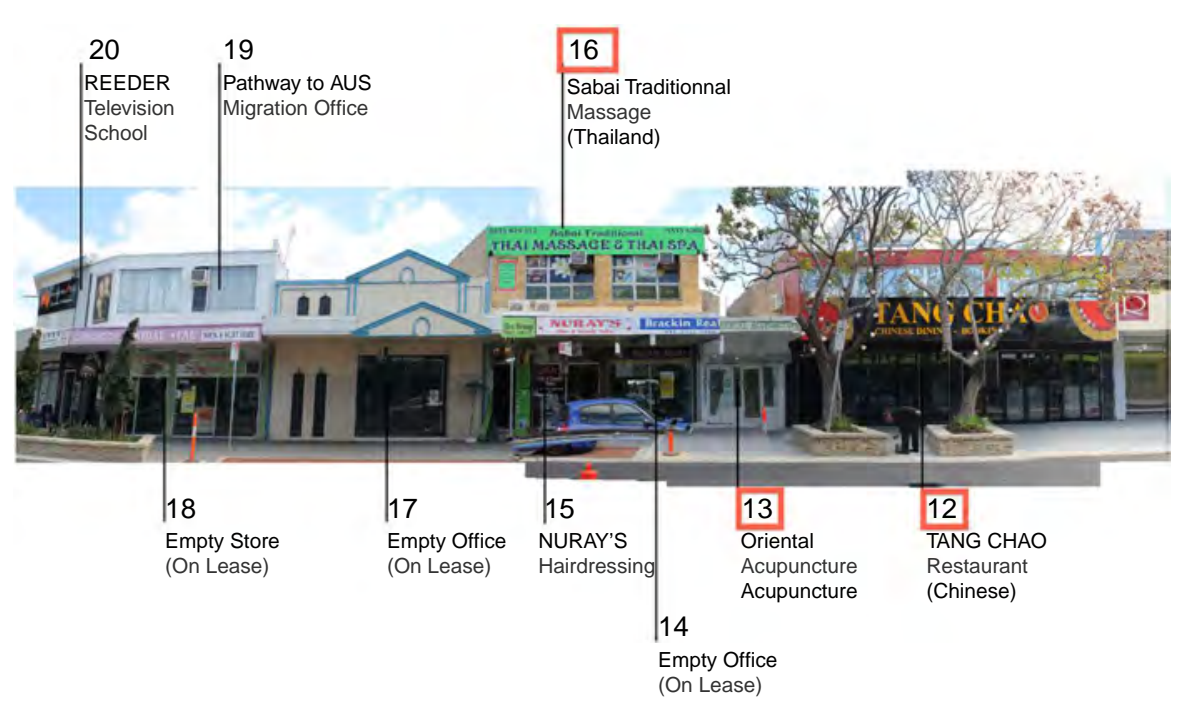

Table I Age

Min (years)

15

16
Max (years)

74

94

Average (years)

Visitor survey respondents $(n=92)$

94

38.43

32.28

Note: Working age population = aged $15-64$ years

Table II Extract of general attitudes towards development impacts and cultural attitudes (both surveys combined)

Strongly disagree/disagree Neither disagree nor agree Agree/strongly agree

(\%)

Existing local businesses will suffer from the Gold Coast

Chinatown development

Gold Coast Chinatown development will result in traffic

congestion, noise, and pollution

Gold Coast Chinatown development will damage the identity

of the urban environment

Gold Coast Chinatown development will change local

traditional culture
(\%)

(\%)

$\begin{array}{lll}39 & 34 & 27 \\ 30 & 42 & 28 \\ 48 & 32 & 20 \\ 44 & 34 & 22\end{array}$

the surveyed respondents visited the Southport Business Precinct as least once a week, which indicates the business precinct has a very reliable and loyal visitor group (see Table III). In summary, only 58 per cent were looking forward to visiting the Gold Coast Chinatown.

Reasons for visiting. According to Table IV the foremost reason given by visitors for their visits to the Southport Business Precinct (where the Gold Coast Chinatown is located) was dining, at 23.40 per cent. Shopping (21.28 per cent) was the next most popular reason followed by work (20.21 per cent), visiting the library (9.57 per cent), and study (8.51 per cent). Very few visitors stated that they came to the Southport Business Precinct to attend 
Table III Frequency of visits $(n=72)$, visitor survey respondents

Frequency

Valid \%

At least once per week

Daily

31.94

Weekly

23

23.61

Two times per week

Often

Several times per week

2-3 times per week

Every workday

Four times per week

3-4 times per week

Table IV Reasons for visiting $(n=94)$

\begin{tabular}{llllllllll} 
Reasons & Dining & Shopping & Work & Visiting library & Study & Medical & Watching movie & Visiting university & Visiting friends \\
\hline Frequency & 22 & 20 & 19 & 9 & 8 & 3 & 2 & 2 & 2 \\
Valid (\%) & 23.40 & 21.28 & 20.21 & 9.57 & 8.51 & 3.19 & 2.13 & 2.13 & 2.13
\end{tabular}

medical appointments (3.19 per cent), or to do other recreational or leisure activities. These results indicate two major groups of visitors to the Gold Coast Chinatown precinct. They are dinners and shoppers who are either tourists or local residents, and workers from nearby business and office locations.

3.2.4 Memorial experiences and comments. What should be featured in Chinatown to make it a memorable experience? In both business and visitor surveys, respondents were asked the above question to investigate what elements were essential to make visiting the Gold Coast Chinatown a memorable experience. The question received quite an interest from the visitors since 61 per cent of them responded, whereas only 32 per cent of the business respondents responded. Although "routine" features of a Chinatown, such as food and visual Asian/Chinese representations were regularly mentioned by respondents ("authentic food shops", "Asian food court", "lanterns and dragons in the traditional sense", and "distinctive physical character" for instance) at an equal proportion (33 per cent each), expressions of culture ("specific style and invitation of cultural traditions", "showing part of a Chinese culture for tourist and locals", and "Asian culture based events") also emerged as an important concern at 29 per cent.

Comments. Although very few survey respondents offered their comments ( $<17$ per cent), the latter are valuable. All but one concerns the development of the Gold Coast Chinatown (only one questions the survey) and not only maps further expectations concerning the Gold Coast Chinatown, but also enlarges the perspectives. For example, it discusses identity within the specific context of the Gold Coast "Trying to create something artificial (a Chinatown without the Chinese) may result in another "amusement park" with no real character nor history"); about ethnicity ("How about making Korea Town instead of Chinatown because there are already many Korean restaurants in Southport and many Koreans living here.") or economic benefits ("I think it's a good card to play to get those new wealthy Chinese middle class over here to spend money"). A detailed analysis of these answers should be very fruitful. 


\subsection{Testing hypotheses using SPSS}

Correlations and ANOVAs was conducted to test seven hypotheses with statistical outputs presented in Tables V, VI and VII accordingly.

Testing H1. The perceived economic impacts of stakeholders affect their development preferences regarding Gold Coast Chinatown.

The business survey displays a medium, positive correlation between the two variables, $r=0.451, n=47, p<0.0005$, with a higher score of positive perceived economic impacts associated with more development preferences regarding the Gold Coast Chinatown. Whereas with the visitor survey, there is a strong, positive correlation between the two variables, $r=0.997$, $n=97, p<0.0005$, with a higher score of positive perceived economic impacts associated with more development preferences regarding the Gold Coast Chinatown.

Testing H2. The cultural attitudes of stakeholders affect their development preferences regarding Gold Coast Chinatown.

The business survey shows a weak, negative correlation between the two variables, $r=-0.067$, $n=47, p<0.0005$, with a higher score of positive cultural attitudes associated with less development preferences regarding the Gold Coast Chinatown, while there is a strong, positive correlation between the two variables, $r=-0.979, n=97, p<0.0005$, with a higher score of

Table V Correlations among development preferences and perceived economic impacts, cultural attitudes, and perceived place attachment

\section{Perceived economic impacts Cultural attitudes Perceived place attachment}

Business survey participants' development preferences

$\begin{array}{lll}0.451^{\star \star} & -0.067^{\star} & 0.253^{\star} \\ 0.997^{\star \star \star} & 0.979^{\star \star \star} & 0.996^{\star \star \star}\end{array}$

Visitor survey participants' development preferences

$0.996^{\star \star \star}$

Notes: Correlation is significant at the 0.01 level (two-tailed). ${ }^{*},{ }^{* *},{ }^{* \star *}$ Small, medium and large correlation $r=0.05-0.29, r=0.30$ to $0.49, r=0.50$ to 1.0 , respectively

Table VI ANOVA for attitude variables (perceived economic impacts, cultural attitudes, and perceived place attachment) and systemic variables (age, income, nationality, and length of residence)

\begin{tabular}{llllll} 
& & Age & Income & Nationality & Length of residence \\
\hline Perceived economic impacts & Business survey & 0.907 & 0.959 & 0.742 & $0.000^{*}$ \\
& Visitor survey & 0.874 & 0.595 & 0.794 & 0.728 \\
Cultural attitudes & Business survey & 0.307 & 0.881 & 0.067 & $0.000^{*}$ \\
Perceived place attachment & Visitor survey & 0.973 & 0.631 & 0.482 & 0.840 \\
& Business survey & 0.589 & 0.925 & 0.405 & 0.584 \\
& Visitor survey & 0.798 & 0.626 & 0.851 & 0.726
\end{tabular}

Note: *Significant at the 0.05 or better probability level

Table VII Correlations between perceived economic impacts and the length of residence, and cultural attitudes and length of residence (business survey)

Length of residence

Perceived economic impacts

$0.979^{\star \star}$

Cultural attitudes

$0.691^{\star *}$

Note: ${ }^{\star \star}$ Correlation is significant at the 0.01 level (two-tailed)

\begin{tabular}{l|l|l} 
PAGE 14 & INTERNATIONAL TOURISM STUDIES ASSOCIATION & VOL. 1 NO. 22015
\end{tabular} 
positive cultural attitudes associated with more development preferences regarding the Gold Coast Chinatown in the visitor survey.

Testing H3. The perceived place attachment of stakeholders affects their development preferences regarding Gold Coast Chinatown.

The business survey reveals a weak, positive correlation between the two variables, $r=0.253$, $n=47, p<0.0005$, with a higher score of positive cultural attitudes associated with more development preferences regarding the Gold Coast Chinatown, in opposition to the visitor survey that shows a strong, positive correlation between the two variables, $r=0.9963, n=97$, $p<0.0005$, with a higher score of positive perceived place attachment associated with more development preferences regarding the Gold Coast Chinatown.

\section{Testing H4-H7}

H4. There is a difference in development preferences regarding Gold Coast Chinatown for young, middle-aged, and old participants.

H5. There is a difference in development preferences regarding Gold Coast Chinatown for low, middle, and high-income participants.

H6. There is a difference in development preferences regarding Gold Coast Chinatown for Australian, Asian, and other nationality participants.

H7. There is a difference in development preferences regarding Gold Coast Chinatown for short, medium, and long-term residence participants.

One-way between-groups analysis of variance (ANOVA) were conducted to explore the impact of age, income, nationality and length of residence on levels of perceived economic impacts, cultural attitudes, and perceived place attachment. Participants were divided into groups according to their age (Group 1: 15-39 years; Group 2: 40-64 years; Group 3: 65 years and above), annual household income before tax (Group 1: <\$25,000; Group 2: \$25,000-\$34,999; Group 3: $\$ 35,000-\$ 49,999$; Group 4: $\$ 50,000-\$ 74,999$; Group 5: $\$ 75,000-\$ 99,999 ;$ Group 6: $\$ 100,000-\$ 149,999 ;$ Group 7: $\$ 150,000$ and above), nationality (Group 1: Australian; Group 2: Asian; Group 3: other) and length of residence (Group 1: <6 months; Group 2: 6-11 months; Group 3: 1-5 years; Group 4: 5 or more years).

In the visitor survey, there was no statistically significant difference found so further correlation analysis was not considered needed because the purpose was to test if there were differences within different groups, and not only to simply test if there is a relationship between each independent variable and each perceived attitude variables (perceived economic impacts, cultural attitudes, and perceived place attachment).

In the business survey, there were statistically significant differences at the $p<0.05$ level in the Perceived Economic Impact scores for the four length of residence groups: $F(2,37)=454.2$, $p=0.000$. Despite reaching statistical significance, the actual difference in mean scores between groups was quite small. Post-hoc comparisons using the Tukey HSD test indicated the mean scores for Group 1, Group 2, Group 3, or Group 4 did not differ significantly from each other.

In the business survey, there was also statistically significant differences at the $p<0.05$ level in the Cultural Attitude scores for the four length of residence groups: $F(2,37)=16.9$, $p=0.000$. Despite reaching statistical significance, the actual difference in mean scores between groups was quite small. Post-hoc comparisons using the Tukey HSD test indicated the mean scores for Group 1, Group 2, Group 3, or Group 4 did not differ significantly from each other.

Further correlation analysis was conducted to explore the relationship between the business survey participants' length of residence and level of their perceived economic impacts and cultural attitudes. For the business survey, there is a strong, positive correlation between the two variables, $r=0.979, n=40, p<0.0005$, with a longer length of residence associated with higher levels of positive perceived economic impacts. A similar result is found for the relationship between the length of residence and cultural attitudes for the business survey: there is a strong, positive correlation between the two variables, $r=0.691, n=40, p<0.0005$, with longer lengths of residence associated with higher levels of positive cultural attitudes. 


\section{Discussion and conclusions}

\section{Limitations and validity}

Although methods for data collection have been selected carefully in consideration of the nature of this research and the specific research objective, there are still limitations within the prescribed methods regarding this research which cannot be avoided. First, the translation of survey participants' responses may have resulted in partial or misinterpreted information because of language barriers. To satisfy Chinese respondents, intercept surveys and drop-off questionnaires were presented in Simplified Chinese language. After completing the fieldwork, survey results were entered into an SPSS database in English; meanwhile, responses to open-ended questions were translated into English for analysis. This language barrier can be somewhat problematic because without doubt the whole variety of nuances from Mandarin are not always easily translated into a foreign language that might not even be comparable of conveying the same kind of variety of ideas, concepts, and terms (Temple and Young, 2004).

Additionally, this research is fraught with difficulties mainly because it is partly concerned with people's attitudes; information about these is reliant on people's own reports in the form of responses to the self-reported questionnaire surveys. These instruments are subject to a number of imperfections, which means that the validity of this data can rarely be certainly relied upon as can be with natural sciences. Because of the "snapshot" feature of surveys in one-shot case studies, intercept surveys and drop-off questionnaires can only collect information from a limited group of respondents from a limited period in time. This may affect the representativeness of the sample. Consequently, broader conclusions cannot be made about the attitudes of the general population. However, the sample number of respondents is not deemed to have statistical significance, and the information is not being used to make generalisations to other populations of visitors or local residents. Instead, the aim of conducting the surveys was to gain an insight into the attitudes of visitors and residents towards the new Chinatown, as well as their suggestions on the development and management practices of the Chinatown.

\section{Conclusions}

The research analysis displays surprising results. First, the Gold Coast Chinatown is unanimously seen or perceived in an extremely positive manner by the different stakeholders and survey respondents. Community attachment, development impact, and cultural attitude largely score above 63 per cent in a positive way, despite some variations related to the status (owner/else; tourist/local). This overall consensus of different stakeholders is quite interesting because when considered in the context of the project development - still in its early stage, with a lack of spatial and symbolic appropriation or identity affirmation - it suggests there is a positive and optimistic attitude towards tourism development. In that sense, it confronts the notion of continuity regarding the concept of cultural sustainability as expressed by Al Hagla (2005). Here, tradition, authenticity, or ethnicity are not perceived as key drivers. Tangible pre-requisites do not appear as a priority for culture-based tourism development.

Yet, only 46.5 per cent of all the respondents believe that the Gold Coast Chinatown will become a favoured destination of the city. As suggested by the results of the open-ended question and comments, could it be analysed also in relation to the spatial characteristics? Although the authenticity of the project does not seem to raise any questions, the fact that respondents often mentioned the lack of physical features (dragons and lanterns for instance), or its relation to historical artefacts (such as traditional gates, and information about Chinese history), or that the visible activities in relation to the Chinatown seem to compromise the perceived vision of a successful project hence its authenticity. This discrepancy between the overall positive attitudes of the project and how it might well succeed or not, not only challenges the traditional weight given to culture and/or heritage in cultural tourism developments, but also the relevance of spatial representations and appropriations as well as the implementation of their mechanisms. As such it also tests the notion of cultural sustainability.

PAGE 16 INTERNATIONAL TOURISM STUDIES ASSOCIATION $\mid$ VOL. 1 NO. 22015 
Second, the correlation results between the three factors used in this study are unanticipated. Correlations of the visitor survey do not show significant difference according to the survey participants' age, income, nationality, and length of residence; this is quite uncommon. In the same way, the fact that for the business survey the longer the length of residence, higher becomes the attitude towards positive perceived economic impacts and positive cultural attitudes: this is the opposite of what is usually found in literature reviews (see e.g. Williams et al., 1995; McCool and Martin, 1994). Could we relate this finding to the broader context of the Gold Coast, a renowned tourism city, a city of entrepreneurs, as well as a city of assortment? Further investigations would be fruitful. One way to do so would be testing the Gold Coast Chinatown case study according to the recent findings established by Soini and Brikeland (2014). The two researchers analysed various scientific discourses on cultural sustainability and evidenced how it is organised around seven storylines in relation to both the political and ideological contexts. They are heritage and vitality for the conservatives, economic viability for the neoliberalists, diversity and place for the communitarians, and eco-cultural resilience and eco-cultural civilisation for the environmentalists. Our results suggest a political and ideological context oscillating between neoliberalism and the environment. It certainly will be interesting to confirm it, as it will help to identify the cultural framework with which the project has been developed and test its adequacy with the policies of the local authorities.

Third, Chinese-ness is an obvious driver, yet the project developers have always claimed a modern Asian Chinatown rather than one solely "Chinese" and authentic. This might explain the present small significance of the discursive representation of Chinese-ness by local authorities. A revised two-factor study process questionnaire (R-SPQ_2F) (Biggs et al., 2001) might help to map the project developers' initial considerations and variations in their conceptualisation of the Chinatown. An investigation on how the Australian born Chinese population of the Gold Coast feels about this project could be interesting to develop with regards to their concept of what an authentic Chinatown on the Gold Coast should be. Although some could see the Chinatown development as another pro-development attitude of the city, and specifically here to take advantage of the economic rise of China, one could actually wonder whether it is not actually re-inventing the concept of a Chinatown in a multicultural and entrepreneurial way. Located in a global and transnational context, further studies involving a more diverse population might redefine the current perspectives.

Lastly, other studies could explore, for instance, whether new mechanisms of spatial appropriation can be invented and whether community territoriality will occur. As such the point is not necessarily to explore the Chinese-ness of this Chinatown but rather to see whether there is sufficient Chinese symbolic imagery for it to be perceived by the locals as a distinct Chinese niche. As such, this case study is resourceful. Nevertheless, it seems also crucial to undertake comparative studies for they will confirm or reject the uniqueness of this case, and most of all contribute to evaluate the nature and the relationship of the cultural sustainability and tourism development under a "Chinese" contemporary context in Australia. Ultimately, it would help us to reconsider the weight of the evaluative factors of community attachment, development impact, and cultural attitude in project development and management.

\section{References}

ABS (2001, 2006, 2011, 2014), "Australian Bureau of Statistic", available at: www.abs.gov.au (accessed September 2014).

Akis, S., Peristianis, N. and Warner, J. (1996), "Residents' attitudes to tourism development: the case of Cyprus", Tourism Management, Vol. 17 No. 7, pp. 481-94.

Al Hagla, K.S. (2005), Cultural Sustainability: An Asset of Cultural Tourism Industry, International Centre for Research on the Economics of Culture, Institutions and Creativity (EBLA), Department of Economics, Universita di Torino.

Andersen, K. (1991), Vancouver's Chinatown: Racial Discourse in Canada, 1875-1980, McGill Queen's University Press, Montreal.

Biggs, J., Kember, D. and Leung, D.Y.P. (2001), "The revised two factor study process questionnaire: R-SPQ-2F", British Journal of Educational Psychology, Vol. 71 No. 1, pp. 133-49. 
Birkeland, I. (2008), "Cultural sustainability: Industrialism, placelessness and the re-animation of place", Ethics Place Environ, Vol. 11 No. 3, pp. 283-97.

Bosman, C. and Dredge, D. (2011), Histories of Placemaking in the Gold Coast City: The Neoliberal Norm, The State Story and the Community Narrative, Urban Research Program, Griffith University, Brisbane.

Brown, G. (2006), "Mapping landscape values and development preferences: a method for tourism and residential development planning", International Journal of Tourism Research, Vol. 8 No. 2, pp. 101-13.

Christiansen, F. (2003), Chinatown, Europe: An Exploration of Overseas Chinese Odentity in the 1990s, Routledge, London.

Chuang, Y.H. and Trémon, A.C. (2013), "Problematizing 'Chinatown': conflicts and narratives surrounding Chinese quarters in and around Paris", in Wong, B. and Tan, C. (Eds), Chinatowns Around the World: Gilded Ghetto, Ethnopolis, and Cultural Diaspora, Koninklijke Brill NV, Leiden, pp. 187-214.

Dedekorkut-Howes, A. and Bosman, C. (2015), "The Gold Coast: Australia's playground?”, Cities, Vol. 42, Part A (February), pp. 70-84, available at: www.sciencedirect.com/science/journal/02642751/42/part/PA

Dredge, D. and Jamal, T. (2013), "Mobilities on the Gold Coast, Australia: implications for destination governance and sustainable tourism", Journal of Sustainable Tourism, Vol. 21 No. 4, pp. 557-79.

Fink, A. (2006), How to Conduct Surveys: A Step-by-Step Guide, 3rd ed., Sage, Thousand Oaks, CA.

Griffin, G. (2006), "The bold and the beautiful: urban heritage and history Gold Coast style", Proceedings of the 8th Australasian UHPH Conference, Massey University, Wellington, 9-11 February.

Harrill, R. (2004), "Residents' attitudes toward tourism development: a literature review with implications for tourism planning”, Journal of Planning Literature, Vol. 18 No. 3, pp. 251-66.

Hawkes, J. (2001), The Fourth Pillar of Sustainability: Culture's Essential Role in Public Planning, Common Ground P/L, Melbourne.

Hearn, A.H. (2013), "Chinatown Havana: one hundred and sixty years below the surface", in Wong, B. and Tan, C. (Eds), Chinatowns Around the World: Gilded Ghetto, Ethnopolis, and Cultural Diaspora, Koninklijke Brill NV, Leiden, pp. 163-86.

Hearne, R.R. and Salinas, Z.M. (2002), "The use of choice experiments in the analysis of tourist preferences for ecotourism development in Costa Rica”, Journal of Environmental Management, Vol. 65 No. 2, pp. 153-63.

Jurowski, C., Uysal, M. and Williams, D.R. (1997), "A theoretical analysis of host community resident reactions to tourism", Journal of Travel Research, Vol. 36 No. 2, pp. 3-11.

Knigge, L. and Cope, M. (2006), "Grounded visualization: integrating the analysis of qualitative and quantitative data through grounded theory and visualization", Environment and Planning, Vol. 38 No. 11, pp. 2021-37.

Lankford, S.V. and Howard, D.R. (1994), "Developing a tourism impact attitude scale", Annals of Tourism Research, Vol. 21 No. 1, pp. 121-39.

Laroche, Y. (2005), "The fourth pillar in three countries: Canada: adapted from the keynote address to the Creative City Network, Canada", Cultural Development Network, the Fourth Pillar of Sustainability: Culture, Engagement and Sustainable Communities proceedings of the Fourth Pillar Conference, Melbourne, November 2004, pp. 42-5.

Lawrence, D.P. (2000), "Planning theories and environmental impact assessment", Environmental Impact Assessment Review, Vol. 20 No. 6, pp. 607-25.

Lindberg, K. and Johnson, R.L. (1997), "Modeling residents attitude toward tourism", Annals of Tourism Research, Vol. 24 No. 2, pp. 402-24.

Liu, Z. (2003), "Sustainable tourism development: a critique", Journal of Sustainable Tourism, Vol. 11 No. 6, pp. 459-75.

Lu, J.C. and Var, T. (1986), "Residents attitude toward tourism impacts in Hawaii", Annals of Travel Research, Vol. 13 No. 2, pp. 193-214.

McCool, S.F. and Martin, S.R. (1994), "Community attachment and attitudes toward tourism development", Journal of Travel Research, Vol. 32 No. 3, pp. 29-34.

McKercher, B., Ho, P.S.Y. and du Cros, H. (2005), "Relationship between tourism and cultural heritage management: evidence from Hong Kong”, Tourism Management, Vol. 26 No 4, pp. 539-48. 
Mason, P. and Cheyne, J. (2000), "Residents' attitudes to proposed tourism development", Annals of Tourism Research, Vol. 27 No. 2, pp. 391-411.

Mota Santos, P. (2013), "Chinatown-Lisbon? Protrait of a globalizing present over a national background", in Wong, B. and Tan, C. (Eds), Chinatowns Around the World: Gilded Ghetto, Ethnopolis, and Cultural Diaspora, Koninklijke Brill NV, Leiden, pp. 215-46.

Murphy, P.E. (1988), "Community driven tourism planning", Tourism Management, Vol. 9 No. 2, pp. 96-104.

Nooteboom, S. (2007), "Impact assessment procedures for sustainable development: a complexity theory perspective", Environmental Impact Assessment Review, Vol. 27 No. 7, pp. 645-5.

Patel, M.X., Doku, V. and Tennakoon, L. (2003), "Challenges in recruitment of research participants", Advances in Psychiatric Treatment, Vol. 9 No. 3, pp. 229-38.

Perdue, R.R., Long. P.T. and Allen, L. (1987), "Rural resident tourism perceptions and attitudes", Annals of Tourism Research, Vol. 14 No. 3, pp. 420-9.

Prentice, R. (1993), "Community-driven tourism planning and residents' preferences", Tourism Management, Vol. 14 No. 3, pp. 218-7.

Saarinen, J. (2006), "Traditions of sustainability in tourism studies”, Annals of Tourism Research, Vol. 33 No 4, pp. 1121-40.

Sharpley, R. (2000), "Tourism and sustainable development: exploring the theoretical divide", Journal of Sustainable Tourism, Vol. 8 No. 1, pp. 1-19

Sheldon, P.J. and Var, T. (1984), "Resident attitudes to tourism in North Wales", Tourism Management, Vol. 5 No. 1, pp. 224-33.

Soini, K. and Birkeland, I. (2014), "Exploring the scientific discourse on cultural sustainability", Geoforum, Vol. 51, pp. 213-23, available at: www.academia.edu/5720777/Exploring_the_scientific_discourse_on_ cultural_sustainability

Spaling, H. and Dekker, A. (1996), "Cultural sustainable development: concepts and principles", available at: www.asa3.org/ASA/PSCF/1996/PSCF12-96SpalingEdit.html (accessed 20 September 2014).

Stevens, J. (1996), Applied Multivariate Statistics for the Social Sciences, 3rd ed., Lawrence Erlbaum, Mahwah, NJ.

Tabachnick, B.G. and Fidell, L.S. (2007), Using Multivariate Statistics, 5th ed., Pearson Education, Boston, MA.

Tan, C. (2013), "Chinatowns: a reflection", in Wong, B. and Tan, C. (Eds), Chinatowns Around the World: Gilded Ghetto, Ethnopolis, and Cultural Diaspora, Koninklijke Brill NV, Leiden pp. 263-84.

Taylor, C. (1991), The Ethics of Authenticity, Harvard University Press, Cambridge, MA, p. 41.

Temple, B. and Young, A. (2004), "Qualitative research and translation dilemmas", Qualitative Research, Vol. 4 No. 2, pp. 161-78.

Thomas, I. and Elliott, M. (2005), Environmental Impact Assessment in Australia: Theory and Practice, Federation Press, Annandale.

Throsby, D. (2008), "Linking cultural and ecological sustainability", International Journal of Diversity in Organizations, Communities and Nations, Vol. 8, No. 1, pp. 15-20.

TRA (2008, 2013, 2014), "Tourism research australia reports", available at: www.tra.gov.au (accessed May and June 2014).

Um, S. and Crompton, J.L. (1987), "Measuring resident's attachment levels in a host community", Journal of Travel Research, Vol. 26, No. 1, pp. 27-9.

Wathern, P. (2004), Environmental Impact Assessment: Theory and Practice, Taylor \& Francis e-Library, available at: https://books.google.com.au/books?id=BtkhD-6zG_wC\&pg=PP4\&lpg=PP4\&dq=Wathern,+P. +\%282004\%29,+Environmental+Impact+Assessment:+Theory+and+Practice,+Taylor+\%26+Francis+ e-Library.\&source=bl\&ots=492DbszdfS\&sig=vG5hdhPUVQMbedDVROpvfVjFVOY\&hl=en\&sa=X\&ei=8fgg VZ38IIPi8gXTwID4CA\&ved=0CCUQ6AEwAQ\#v=onepage\&q=Wathern\%2C\%20P.\%20(2004)\%2C\% 20Environmental\%20Impact\%20Assessment\%3A\%20Theory\%20and\%20Practice\%2C\%20Taylor\% 20\%26\%20Francis\%20e-Library.\&f=false 
Weaver, D. and Lawton, L. (2004), "Visitor attitudes toward tourism development and product integration in an Australian urban-rural fringe”, Journal of Travel Research, Vol. 42 No. 3, pp. 286-96.

Williams, D.R., McDonald, C.D., Riden, C.M. and Uyssal, M. (1995), "Community attachment, regional identity and resident attitudes towards tourism", Proceedings of the 26th Annual Travel and Tourism Research Association Conference Proceedings, Travel and Tourism Association, Wheat Ridge, pp. 424-8.

Wise, P. (2006), "Australia's Gold Coast: a city producing itself”, in Linder, C. (Ed.), Urban Space and Cityscapes: Perspectives from Modern and Contemporary Culture, Routledge, London, pp. 177-291.

Wong, M.R. (2004), Sweet Cakes, Long Journey: The Chinatowns of Portland, Oregon, University of Washington Press, Seattle, WA.

Woon K.K., Wan-Ling, C.J.W. and Chia, K. (2000), Rethinking Chinatown and Heritage Conservation in Singapore, Singapore Heritage Society, Singapore.

Wu, J. (1928/1991), Chinatowns: Accommodation and Assimilation, Tianjin Renmin Publishing House, Tianjin.

\section{Further reading}

Andriotis, K. (2005), "Community groups' perceptions of and preferences for tourism development: evidence from Crete", Journal of Hospitality \& Tourism Research, Vol. 29 No. 1, pp. 67-90.

City of Gold Coast (2013), "Gold Coast Chinatown", available at: www.goldcoast.qld.gov.au/gold-coastchinatown-17077.html (accessed 28 January 2015).

Simm, C. (2015), "Positive \& negative effects of tourism”, available at: http://traveltips.usatoday.com/positivenegative-effects-tourism-63336.html (accessed 28 January 2015).

United Nations Environment Programme (UNEP) (2015), "Impacts of tourism", available at: www.unep.org/ resourceefficiency/Business/SectoralActivities/Tourism/FactsandFiguresaboutTourism/ImpactsofTourism/ tabid/78774/Default.aspx (accessed 28 January 2015).

\section{About the authors}

Karine Dupre is an Associate Professor at the Griffith University, Australia. Her current research interests focus on the impact of tourism in city development, architectural and cultural sustainability, and place-making in general and symbolic values like place attachment and appropriation in specific. Dr Karine Dupre is the corresponding author and can be contacted at: k.dupre@griffith.edu.au

Bixia Xu is an Endeavour Fellowship at the Griffith University, Australia. Her research interests are environmental planning, cultural tourism and climate change adaptation.

For instructions on how to order reprints of this article, please visit our website:

www.emeraldgrouppublishing.com/licensing/reprints.htm

Or contact us for further details: permissions@emeraldinsight.com 